Hispania Sacra, LX

122, julio-diciembre 2008, 423-443, ISSN: 0018-215-X

\title{
CRISIS ECONÓMICA E IDENTIDAD RELIGIOSA DE UN MONASTERIO FEMENINO EN ÉPOCA DE LOS AUSTRIAS: SANTA CATALINA DE CÓRDOBA DEL TUCUMÁN (1613-1700)
}

\author{
POR \\ GUILLERMO NIEVA OCAMPO \\ Universidad Nacional del Sur, Argentina
}

\begin{abstract}
RESUMEN
En el año 1613, doña Leonor de Tejeda y Miraval, asistida por el obispo del Tucumán don Fernando de Trejo y Sanabria y los padres de la Compañía de Jesús, fundaba en Córdoba un monasterio para hijas y nietas de conquistadores. Para poder cumplir con sus objetivos fundamentales -la clausura y las cargas espirituales- doña Leonor dotó sobradamente con sus bienes a la nueva fundación. De ese modo, el monasterio se transformó rápidamente en una activa unidad de intercambios y de crédito. Sin embargo, las dificultades estructurales de la economía local en la segunda mitad del siglo XVII afectaron significativamente la estructura y la identidad de la comunidad monástica.
\end{abstract}

PALABRAS ClAVE: Monjas dominicas, Tucumán, Siglo XVII, economía colonial, Crédito eclesiástico.

\section{ECONOMIC CRISIS AND RELIGIOUS IDENTITY OF A FEMALE MONASTERY DURING THE AUSTRIAN DYNASTY: SAINT CATHERINE OF CÓRDOBA OF TUCUMÁN (1613-1700)}

\begin{abstract}
In 1613, Mrs. Leonor de Tejeda y Miraval, supported by the bishop of Tucumán Province, Mr. Fernando de Trejo y Sanabria and by the heads of the Society of Jesus, founded a monastery for daughters and granddaughters of conquerors in Córdoba City. In order to be able to fulfill its main objectives -the closure and the spiritual loads-Mrs. Leonor fully equipped the new foundation.
\end{abstract}


In this way, the monastery rapidly became an active unit of interchange and credit. However, the structural difficulties of local economy in the middle of 17th century greatly affected both the structure and the identity of the monastic community.

KEY WORDS: Dominican Nuns, Tucumán, $17^{\text {th }}$ Century, Colonial Economy, Ecclesiastical credit.

Recibido/Received 08-01-2008

Aceptado/Accepted 10-03-2008

Este trabajo aborda el estudio del monasterio de Santa Catalina de Córdoba del Tucumán entre los años 1613 y 1700, entendido como una activa unidad de intercambios y de crédito. A través de nuestro análisis nos proponemos ver cómo las fluctuaciones que sufre la economía de la Gobernación del Tucumán condiciona la vida conventual, a tal punto que las dificultades estructurales de dicha economía regional en la segunda mitad del siglo XVII afectaron significativamente no sólo la estructura del convento, sino incluso la misma identidad de la comunidad monástica. De este modo, iniciaremos nuestra exposición con una breve referencia a la fundación del monasterio para dar paso, a continuación, a una descripción de los bienes dotales agregados por la fundadora, así como a las condiciones económicas de la fundación. Desarrollaremos el nudo del estudio a partir del análisis de la economía monástica en la primera mitad del siglo XVII para, finalmente, explicar la mutación que se produce en la comunidad de monjas de Santa Catalina en la segunda mitad de dicha centuria a partir de los cambios coyunturales experimentados por la región.

Frente a los rasgos y contornos que con el paso del tiempo adopta un monasterio calzado en época de los Austrias, como es el caso que presentamos, nuestro deseo es el de ofrecer a la comunidad académica una explicación integral y distinta a la expresada con la simple sentencia moral «estado de relajación de la observancia regular» que dieron sobre el monasterio tucumano los reformadores del siglo XVIII. Concepto para nada original que ofrece un diagnóstico y una explicación insuficientes de un complejo fenómeno social.

\section{DoÑa LeONOR DE TEJEDA Y MiRAVAL}

Hija del conquistador Tristán de Tejeda, nieta de Hernando Mejía de Miraval, doña Leonor de Tejeda había nacido en Tucumán. Fue llevada a la ciudad de Córdoba en 1574 donde contrajo matrimonio con un adinerado y distinguido encomendero, don Manuel de Fonseca y Contreras ${ }^{1}$. Influenciados por los Padres de la

\footnotetext{
${ }^{1}$ La conjunción de individuos dotados simultáneamente con títulos de Castilla, mercedes de tierras y encomiendas de indios, llevó a la constitución en Córdoba del Tucumán de una aristocracia local que

Hispania Sacra, LX

122, julio-diciembre 2008, 423-443, ISSN: 0018-215-X
} 
Compañía de Jesús, que habían iniciado en la ciudad una feroz campaña contra la encomienda indígena, este matrimonio comenzó a meditar la idea de fundar un monasterio para hijas y nietas de conquistadores ${ }^{2}$. Leonor ya había abierto su hogar para la educación de niñas en Córdoba y Fonseca se dedicó a construir un espacioso edificio que pudiera servir como convento. Una larga enfermedad que afectaba y mermaba las fuerzas de su marido, así como los consejos del provincial de los jesuitas, el padre Diego de Torres Bollo, decidieron a doña Leonor, inmediatamente después de la muerte de su esposo, a pedir la ayuda del obispo Hernando de Trejo y Sanabria, que fue a Córdoba y con entusiasmo aprobó el proyecto de fundar un convento de hermanas de la Orden dominica en Córdoba ${ }^{3}$.

Con la anuencia del cabildo local, del obispo y del Rey -que mediante una real cédula expedida en marzo de 1613 autorizaba la fundación- se dio inicio al monasterio de Santa Catalina de Siena. A pesar de la falta de antecedentes o de siquiera una copia de las reglas de la orden, se convocó una conferencia eclesiástica y se improvisaron las pautas necesarias. Los jesuitas y el obispo se encargaron de componer un estatuto que en general seguía la regla de Santa Teresa, salvo en cuatro artículos. Sin embargo, la muerte de Trejo y la enemistad entre su sucesor, Julián de Cortázar, y los jesuitas, provocaron el alejamiento de estos últimos de la dirección espiritual de las monjas ${ }^{4}$. Para entonces las religio-

inmediatamente se abocó a la creación de linajes y, sobre todo, a la reproducción de los modos de vida de la nobleza media castellana. Véase, P. Bustos Argañaraz, «El Patriciado de Córdoba. Contribución al estudio de su génesis», Boletín del Centro de Estudios Genealógicos de Córdoba, n 27 (1998), pp. 13-73; A. Moyano Aliaga (coord.), Don Jerónimo Luis de Cabrera, 1528-1574. Origen y descendencia, Alción Editora/Centro de Estudios Genealógicos de Córdoba/Fundación Rafael del Pino, Córdoba, 2003.

2 J. Gracia, Los Jesuitas en Córdoba, Buenos Aires, Espasa-Calpe, 1940, pp. 75-86. En Hispanoamérica, los fundadores y patronos fueron en general hombres y mujeres de fortuna que se habían enriquecido con la minería, el comercio o la agricultura y deseaban satisfacer sus aspiraciones religiosas y sociales, muestra de la vinculación e incluso dependencia del mundo conventual de los ideales y de las representaciones sociales que los laicos habían elaborado acerca de la vida consagrada. Véase, Asunción LaVrin, «Religiosas», en S. Schell Hoberman, , S. Migden Socolow (comp.), Ciudades y sociedades en Latinoamérica colonial, Buenos Aires, FCE, 1992, pp. 179-213.

3 J. C. Vera Vallejo, Breve Historia del monasterio de Santa Catalina de Sena en la ciudad de Córdoba, Córdoba, Imprenta Gutemberg, 1942, pp.82-106. La Gobernación del Tucumán, dependiente de la Audiencia Real de Charcas, había sido constituida en el año 1563. Por su parte, el obispado del Tucumán, sufragáneo de la Archidiócesis de Charcas, había sido creado en el año 1570. La sede episcopal, desde su fundación hasta el año 1699, fue la ciudad de Santiago del Estero, en ese último año se trasladó a la ciudad de Córdoba.

${ }^{4}$ Los Jesuitas del Tucumán tuvieron un gran interés en la fundación y en la formación de un monasterio de monjas para las hijas de los conquistadores. De hecho, hacia 1607 habían proyectado una primera fundación con monjas traídas de Chile. Asimismo, después que lograron la fundación del monasterio de Santa Catalina, destinaron al maestro de novicios del Colegio que tenían en Córdoba para asistir en la formación de las monjas, ya que no se consiguió que religiosas de otros monasterios del Virreinato del Perú pudieran trasladarse hasta Córdoba para iniciar en la vida monástica a las nuevas reclutas. Sin embargo, hacia 1623, las Catalinas optaron por desconocer los consejos de los Padres quie- 
sas cargaban con una acusación de falsedad, ya que se decía que no eran monjas, por no pertenecer a ninguna orden religiosa aprobada. Finalmente, gracias a la intervención de Urbano VIII, en 1625, se suspendió la regla que hasta entonces habían observado y pudieron profesar según la regla de Santo Domingo ${ }^{5}$.

\section{LA DOTACIÓN}

Indudablemente doña Leonor de Tejeda, elegida en reiteradas ocasiones priora de la nueva comunidad, fue una dama piadosa. Sin embargo, al igual que otras mujeres de su rango, consideradas «hacendosas y acrecentadoras de sus haciendas», fue también emprendedora, diligente y hábil en la administración de sus bienes 6 . De hecho, antes de ingresar en la vida monástica (e incluso después) participó activamente en el comercio de mulas y en la venta de esclavos, negocios sumamente lucrativos en ese período ${ }^{7}$. En su condición de viuda tenía un derecho eminente sobre sus bienes y los heredados de su marido. Los que puso a disposición de la nueva fundación, en la que además había ingresado como novicia y como primera priora ${ }^{8}$.

Para evitar la precariedad de la fundación y sobre todo para que el monasterio pudiera cumplir con sus fines constitutivos, o sea las cargas espirituales y la clausura, doña Leonor previno la dotación económica del monasterio con unas

nes, por orden del Prepósito General Muzio Vitteleschi, se retiraron definitivamente en el año 1627de la asistencia que les prestaban. M. M. Morales (ed.), A mis manos han llegado. Cartas de los PP. Generales a la Antigua Provincia del Paraguay (1608-1639), Madrid, Universidad Pontifica Comillas, 2005, pp. 39, 132, 182, 206, 284 y 358.

${ }_{5}^{5}$ Archivo del Arzobispado de Córdoba (en adelante AAC), Catalinas, Rollo 1, Historia del Monasterio Senense de la Ciudad de Córdoba en la Provincia del Tucumán, p. 106 y ss.

${ }^{6}$ En el imaginario social hispánico, toda mujer casada o viuda -aquella que tenía bienes y ciertos derechos para administrarlos- debía ser regente de la casa y del orden de la familia y, además, debía «velar sobre las criadas y el repartir las tareas y las raciones», L. de LEón, La perfecta casada, Espasa Calpe, Madrid, 1980 (original, 1583), pp. 52 y 53.

${ }^{7}$ Archivo Histórico de la Provincia de Córdoba (AHPC), Reg. № 1, Protocolos notariales 16121613, f. 286v-286r, 106r-107v.

${ }^{8}$ La acción de doña Leonor de Tejeda, al renunciar al mundo y dotar con sus propios bienes una comunidad monástica, no era extraña al comportamiento social que se esperaba de una señora de su rango en la sociedad hispánica de la época de los Austria, pero no por ello dejaba de resultar extraordinaria. De todos modos, en el Tucumán a principios del siglo XVII, una española viuda se veía obligada a optar por el estado religioso o por un nuevo matrimonio, ya que la viudez ininterrumpida colocaba a esas «mujeres solas» en una situación de debilidad social extrema, que bien podía derivar en el amancebamiento y, con ello, en el deshonor de todo el linaje. Véase, M. Rivero Rodríguez, La España de Don Quijote. Un viaje al Siglo de Oro, Madrid Alianza Editorial, 2005, p. 306; Roxana BOIXADÓS, «Una viuda de mala vida en la colonia riojana», en F. Gil LozAno, V. S. PITA, M. G. InI, Historia de las mujeres en Argentina. Colonia y siglo XIX, Buenos Aires, Taurus, 2000, pp. 135-151.

Hispania Sacra, LX

122, julio-diciembre 2008, 423-443, ISSN: 0018-215-X 
rentas cuantiosas y sobradas ${ }^{9}$. Es cierto que se contravino la orden de Felipe III que, aconsejado por el dominico Hernando de Mejía, había dispuesto que los veinte mil ducados que costaría la fundación se pudieran tomar de las encomiendas de indios que quedaran vacantes, «por un año, o lo que conviniere que estén vacas y que estas bacantes se aplicasen por la obra y fundación del dcho Convento pues por ser interesados todos en obra tan de servicio de Dios nro señor lo tennian por bien» ${ }^{0}$. Pero ya sea la fundadora, como los padres jesuitas y el mismo obispo no iban a transigir en el empleo de mano de obra indígena para el mantenimiento de la nueva comunidad religiosa, justamente cuando estaban empeñados en una cruzada contra el la encomienda de servicio personal y el mal trato al indígena ${ }^{11}$.

En el caso que nos ocupa, la dotación efectuada se ajusta a las pautas dotales tradicionales, dividiendo su contenido en cuatro grandes apartados: la cesión de los inmuebles donde iba a instalarse la comunidad; las propiedades rurales y las rentas en dinero, destinadas al mantenimiento comunitario y al culto divino; los objetos de uso cotidiano de las monjas y, por último, los objetos y ornamentos destinados a la iglesia. Y es que el sostenimiento de un monasterio femenino requería de sumas fuertes de dinero, ya que, además de instalar a las religiosas en una casa amplia y conveniente, se tenía que pagar la alimentación, el vestido y el calzado de las monjas; cubrir los salarios de las sirvientas, del padre capellán, del mayordomo, del médico, del boticario, del cirujano, del barbero y del administrador, entre otros; mantener los edificios, solventar los gastos de celebración de misas y del culto, así como costear los posibles pleitos y los litigios.

En virtud de todo ello, la madre Catalina de Sena, reservándose los derechos que le correspondían como patrona ${ }^{12}$, legó todos sus bienes al monasterio, a sa-

\footnotetext{
${ }^{9}$ Respecto a las cargas espirituales, las rentas dotales se entregaban a cambio de la celebración de las memorias de misas y capellanías que los patronos fundan para la salvación de su alma; en cuanto a la clausura, la dotación económica debía asegurar un nivel de rentas suficiente para evitar que las monjas tengan que acudir a recursos extraordinarios para su subsistencia, que impidan el absoluto mantenimiento de la clausura, con actividades como las granjerías, la limosna o las devociones de particulares que frecuentaban los conventos.

${ }^{10} \mathrm{AAC}$, Catalinas, Rollo 5, Real Cédula expedida sobre la fundación de este Monasterio por nuestro Catholico Monarcha que fue el año de 1613, mandando se le remitiese la Relación que en ella se expresa, por el Illo. Sr. Obispo que no fue de esta Provincia Dn. Fray Hernando Mexía del Orden de Predicadores procurador (en la cita conservamos la grafía original).

${ }^{11}$ Los jesuitas mantendrían la oposición hacia la encomienda de servicio personal hasta 1650 aproximadamente. Sobre la explotación de los indios sometidos del Tucumán y la batalla contra el servicio personal véase, Silvia PALOMEQUE, «El mundo indígena. Siglos XVI-XVIII», en E. TÁNDETER, Nueva Historia Argentina, Buenos Aires, Sudamericana, 2000, pp. 89-143.

12 Entre los derechos del patrono figuraban: nombrar capellán, elegir al mayordomo, disponer su paga y administrar los bienes conventuales con él, que se digan misas todos los domingos por ella, por la memoria de su marido y por los indios de sus encomiendas, etc.
} 
ber: una casa grande y buena con cuatro solares en el centro de la ciudad, tres de ellos ocupados con viñas, huertas y una acequia; más un molino y otra manzana en la traza de la ciudad con huertas; un tejar a un cuarto de legua, sobre el río; una estancia llamada Guamacha ${ }^{13}$, donde se producía maíz, trigo y había buena pesca; otra estancia en Calamuchita, con indios encomendados; otra estancia llamada Macha, a doce leguas al norte, con abundante ganado (300 vacas, 200 yeguas, 150 mulas, 29 garañones y burras, 396 cabras, 2400 ovejas, 100 cerdos y 30 bueyes), diez carretas, cuatro piezas de esclavos «más otro esclavo oficial tejero casado, con su mujer y un hijo», vajilla, tapices, manteles, lámparas, óleos y retablos, cruces y objetos de imaginería; una escritura de censo contra Bernardina de Miraval, que por ella debía 5.307 pesos. Finalmente, completaba el legado con el ajuar de su casa (cajas, sillas, bufetes, camas, cujas, etc.), una alfombra de Castilla, más telas, una alquitara, un hornillo de fierro y cuatro caballos ${ }^{14}$.

Por último, estableció las condiciones que debían presidir la administración hacendística de la comunidad, con el fin de conservar y, si era posible, aumentar la dotación económica por ella otorgada. De ese modo, se institucionalizó la figura del mayordomo para el cobro de las rentas y demás diligencias económicas, quien percibiría de las monjas un sueldo establecido por la patrona ${ }^{15}$. El primero en ser designado, por el espacio de ocho años, fue un hombre del entorno de doña Leonor, el Alférez Miguel Gerónimo Maldonado ${ }^{16}$. Para administrar el dinero líquido procedente de las dotes aportadas por las monjas, de sus herencias transversales o de las redenciones de censos, el mayordomo debía consultar siempre el parecer de la fundadora. Además de la administración de la cuantiosa dotación otorgada por la Tejeda, el mayordomo se tenía que encargar de los bienes aportados por las demás monjas, aquellos previstos por las constituciones y también los que ellas, sus padres u otros allegados al monasterio fueran aportando en donación.

${ }^{13}$ En gran parte del siglo XVII, en la jurisdicción de la ciudad de Córdoba, las grandes y medianas unidades de producción rural se denominaron estancias, estuvieran o no dedicadas en exclusividad a la ganadería, la agricultura o la producción mixta. Véase, C. GonZÁLEZ NAVARRo, Construcción social del espacio en las sierras y planicies cordobesas, Tesis doctoral inédita, Universidad Nacional de Córdoba, 2005, pp. 254-261.

${ }^{14}$ Leonor puso además como condición, que tras su muerte le sucediera en el patronato su hermano Juan de Tejeda y sus descendientes o, en el caso que no los tuviera, «suceda en el dicho Patronazgo el varón mas cercano a la casa del dicho mi padre, prefiriendo los mayores a los menores, para siempre jamás». El testamento de doña Leonor de Tejeda ha sido publicado por R. LEvILLIER (dir.), Papeles eclesiásticos del Tucumán. Documentos originales del Archivo de Indias, vol. II, Madrid,Imprenta de Juan Puello, 1926, pp. 403-414 (en adelante Testamento).

${ }_{15}$ Con el cambio de regla en 1625 pasó a llamarse Síndico Procurador.

${ }_{16}$ AHPC, R. 1, Prot. 1613, f. 193R-196R

Hispania Sacra, LX

122, julio-diciembre 2008, 423-443, ISSN: 0018-215-X 
Respecto a la dote, se había establecido que cada monja de velo negro (coro) debía pagar 1500 pesos en reales «o se han de imponer sobre buenas posesiones a censo con fianzas seguras». Se comprometían a concurrir también con otros 200 pesos «para el ajuar sin cama y hábito», así como 75 pesos más por el año de noviciado «la mitad cuando entrasen y la otra mitad a los seis meses siguientes». Mientras que las monjas de velo blanco (legas) debían pagar como dote 500 pesos «o a censo como dicho es, y su cama y hábito; y por el año de noviciado treinta pesos en dinero o cosas de la tierra necesarias para el dicho convento». De ese modo, las disposiciones estatutarias salían al encuentro de las condiciones económicas de las reclutas de la primera comunidad, quienes realizaron los pagos de sus dotes con dinero o con censos sobre alguna propiedad familiar ${ }^{17}$.

Al segundo grupo de bienes incorporados al monasterio corresponden las donaciones. En general se trató de un renglón económico muy dispar, que incluía desde la entrega de enseres domésticos a la de animales de tiro, como las «cinco mulas chúcaras» que dio Juan Arballo de Albornoz el 1 de julio de 1613 en pago de la legítima de su hermana Juana de Albornoz ${ }^{18}$. Mucho más espectacular fue la que hizo doña Clara de Tejeda, la hermana de la fundadora y monja catalina, quien legó en 1622 al monasterio su herencia legítima cuyos bienes ascendían a la espectacular suma de 27.000 pesos $^{19}$.

\section{INTERCAMBIOS, CRÉDITO Y GASTOS HASTA 1650}

De las 166 monjas que profesaron a lo largo del siglo XVII en el monasterio de Santa Catalina, 62 lo hicieron entre 1614 y $1649^{20}$. La cifra de los primeros años es alta, con una media de 10 profesiones por lustro entre 1614 y 1635 . Sin embargo, a partir de esa última fecha el crecimiento se desaceleró a raíz de la

17 AHPC, R. 1, Prot. 1613, f. 151v-155r, 206v-207v, 230v-231r, 280v-282v; Prot. 1614, f. 240v246r. En el momento de la fundación la madre Catalina de Sena se había reservado el privilegio de dar el hábito a «cuatro monjas de velo negro, y para el coro, y una sargenta [lega] todas sin dote, de limosna por ser pobres y tenerles obligación».

18 AHPC, R. 1, Prot. 1613, f. 148v-151v.

19 Doña Clara de Tejeda se había propuesto fundar un monasterio de clarisas en la ciudad, empresa que resultó fallida. Finalmente profesó como monja dominica y legó al monasterio su legítima de padre y madre. El testamento de doña Clara ha sido publicado en R. LEVILLIER (dir.), Papeles eclesiásticos del Tucumán. Documentos originales del Archivo de Indias, vol. II, Madrid,Imprenta de Juan Puello, 1926, pp. 421-434.

20 Todos los datos demográficos de la comunidad dominica han sido extraídos de la Tabla cronológica que propone todas las religiosas que desde la Fundación hasta nuestros tiempos han profesado en el monasterio de Santa Catalina de Sena de la ciudad de Córdoba, AAC, Catalinas, Rollo 1. 
epidemia que asoló la ciudad entre 1635 y $1637^{21}$. Finalmente, la tendencia fue tímidamente alcista a partir de 1645. Según una escritura que firmaron en 1641, las monjas con derecho a voto en capítulo eran 21, cifra que doblarían con holgura en la segunda mitad del siglo 22 .

Gracias a que el número de monjas y de sus sirvientas enclaustradas era relativamente bajo, a que los bienes aportados por la fundadora eran sustanciosos y a que las rentas todavía eran pagadas con puntualidad, podemos concluir que la solvencia económica parece ser la tónica general de la primera mitad del siglo XVII. De hecho, en 1623 encontramos al capítulo conventual negociando a través de un procurador en la corte de Madrid la autorización del Rey para introducir por el puerto de Buenos Aires cincuenta esclavos de Guinea, germen de la populosa ranchería de las Catalinas ${ }^{23}$. En esos años el precio de una pieza de ese género costaba alrededor de 400 pesos, por lo tanto las monjas disponían de la fabulosa cantidad de 20.000 pesos $^{24}$. Claro está que a partir de 1635 fue más difícil equilibrar el presupuesto, a causa de la peste, pero sobre todo a raíz de los gastos que ocasionó el traslado del monasterio a un nuevo edificio. Sin embargo, la ayuda económica que aportó el obispo devolvió una relativa prosperidad a la comunidad monástica, sellada con las fabulosas fiestas de inauguración de la nueva iglesia en 1652, como veremos más adelante.

Los registros que realizó la procuradora del convento entre los años 1647 y 1652 ponen al descubierto las transacciones económicas y los bienes que consumía la comunidad, así como la red social que sustentaba ese intercambio, ofreciéndonos un paisaje general de la economía de las Catalinas ${ }^{25}$. Por esos años las monjas compraron cada mes a algunos vecinos de la ciudad novillos a dos pesos cada uno, varas de lienzo a diez reales la vara, varas de cordellate a diez reales la vara, fanegas de maíz de los Jesuitas a cuatro pesos la fanega y

\footnotetext{
${ }^{21}$ Durante los años que duró la peste no profesó monja alguna. La Gobernación padeció también, a lo largo de esos años, el así llamado Gran Alzamiento o Segunda Guerra Calchaquí (1630-1643). Sobre la epidemia véase, J. GRACIA, Op. Cit., pp. 247-252.

22 AHPC, R. 1, Prot. 1641-1642, fol. 93. Las primeras constituciones situaban el máximo de profesas permitidas en 21, mientras que las constituciones dominicas lo elevaron al número de 40.

${ }^{23}$ R. Levillier, Correspondencia de la Ciudad de Buenos Aires con los Reyes de España, vol. I, Buenos Aires, Municipalidad de Buenos Aires, 1915, p. 228.

${ }^{24}$ En Córdoba, centro redistribuidor de mercancías hacia el norte desde finales del siglo XVI, el negocio esclavista funcionaba a través de compañías conformadas por cordobeses (españoles o criollos) y portugueses que ingresaban las piezas por el puerto de Buenos Aires. Véase, C. Sempat AssaDOURIAN, El tráfico de esclavos en Córdoba (1588-1610). Según las actas de protocolos del archivo histórico de Córdoba, Córdoba, Universidad Nacional de Córdoba, 1965.

${ }^{25}$ AAC, Catalinas, Rollo 4, Libro de la Procuradora. Los oficios en el monasterio de Santa Catalina eran diecisiete. Mientras que las depositarias se encargaban de la inversión del dinero de las dotes, de la suerte de las propiedades y de organizar las finanzas, la procuradora debía hacer las compras de los artículos de despensa, vestuario, enfermería y sacristía, así como recibir el dinero que ingresaba por diversos renglones. De todo ello debía rendir cuenta a la madre priora.
}

Hispania Sacra, LX

122, julio-diciembre 2008, 423-443, ISSN: 0018-215-X 
también harina. Además, recibieron del maestre de campo Diego Fernández Salguero, 2.525 tejas que a 25 pesos monta 255 pesos y 5 reales, para la construcción de la iglesia, compra que se completó con algunos sayales y novillos.

En términos generales, las monjas siempre pagaron esas compras con numerario (pesos de a ocho) haciendo apetecible el trato comercial con ellas. Por ejemplo, entre octubre de 1646 y abril de 1648 las monjas compraron ciento diez fanegas de cal a Diego Celis de Quiroga, que le fueron pagadas con el dinero obtenido por la venta de algunas mulas.

Pero no todo eran erogaciones para la madre procuradora. Entre sus anotaciones figuran como entradas para el convento una serie de bienes -en general en especie- obtenidos como remuneración por diversos servicios y deudas que los habitantes de la ciudad tenían con el monasterio de Santa Catalina. A veces se trataba del pago del piso y la dote por tener dentro del convento a una novicia, tasa que según las constituciones ascendían a 1.500 pesos de reales para las monjas de velo negro y a 500 pesos de reales para las monjas de velo blanco.

Don Diego Nuñez, por ejemplo, dio a la procuradora a lo largo del año 1647 -durante el noviciado de su sobrina- cincuenta carneros, cada uno a seis reales, más diversos géneros de tela (ruan, gasa para velo negro, picote blanco, lienzo, servillos, etc.) y dinero (seis pesos). Por el mismo motivo, don Domingo Gómez dio al monasterio treinta pesos en reales el día que su hija tomó el hábito. Además, en los meses siguiente entregó a las monjas dos arrobas de algodón a cinco pesos la arroba, una fanega y media y cuatro almudes de maíz a siete reales el almud, diez pesos y medio de judiguelos, dos arrobas más de algodón -ya en 1648 - a cuatro pesos la arroba y una fanega y media de frijoles a diez pesos la fanega.

Por otra parte, algunas transacciones correspondían al pago que realizaban -siempre a la procuradora- los individuos que se beneficiaban con el crédito en metálico otorgado por el monasterio. De hecho, el monasterio de las Catalinas se había convertido rápidamente en una entidad crediticia visitada con mucha frecuencia por la elite local, del mismo modo que sucedía con otros monasterios femeninos en otros puntos de la Monarquía Hispánica en América ${ }^{26}$. Tal carácter derivaba del las mismas disposiciones que había dictado la fundadora:

${ }^{26}$ Los estudios sobre el tema son cada vez más numerosos. Entre ellos destacan, Elizabeth LEHFELDT, «A Convents as Litigants: Dowry and Inheritance Disputes in Early-Modern Spain», Journal of Social History, 33, n 3 (2000), pp. 645-664; Kathryn BuRNs, «Apuntes sobre la economía conventual: el monasterio de Santa Clara del Cusco», Allpanchis, 38 (1991), pp. 67-95; Ramón María SERRERA, «El convento de la Concepción de Caracas y el crédito agrario en el nacimiento de la economía del cacao en Venezuela (siglo XVII)», en La Orden Concepcionista. Actas del I Congreso Internacional, t. I, León, Universidad de León, 1990, pp. 537-554; María Antonia Triano, «Función económica de los monasterios de clausura en la audiencia de Charcas», en J. PANIAGUA PÉrez y M. I. VIFORCos MARINAS (coord.), I Congreso Internacional de Monacato Femenino en España, Portugal y América, t. I, León, 
«Se ha de censurar lo tocante a la seguridad de las dotes de las dichas monjas y sarjentas (legas) en la seguridad de las posesiones sobre que los han de imponer y afianzar, que han de dar con el señor Reverendisimo [el obispo], estando en esta ciudad, y con sus sucesores, y por su ausencia con el vicario que ahora o por tiempo fuere para que aceptando las dichas posesiones e fianzas se otorguen las escrituras necesarias en favor de dicho convento» 27 .

Por lo tanto, el numerario recibido en ese concepto se invertía en alguna rama productiva y los réditos se destinaban a cubrir los gastos de mantenimiento ${ }^{28}$. Las dotes debían entregarse en efectivo, pero también se daba el caso, tal como hemos visto, que se recibieran «moneda de la tierra» por un valor equivalente o algún documento de crédito, como por ejemplo un censo consignativo impuesto sobre alguno de los bienes del donante, fórmula utilizada también para la concesión préstamos ${ }^{29}$.

Universidad de León, 1993, pp. 441-451; María del Carmen BURGO LóPEZ, «Política económica y gestión administrativa en las entidades monásticas femeninas», Ibidem, t. II, pp. 569-585.

${ }^{27}$ Testamento, p. 409. El derecho Canónico terminó por precisar y consolidar esta práctica: A la muerte de la religiosa, aunque ésta sólo haya hecho los votos temporales, la dote irrevocablemente quedaba como propiedad del monasterio o de la religión, (Canon 548). Que después de la primera profesión de la religiosa, la Superiora, con su Consejo y con el consentimiento del ordinario del lugar, debe colocar la dote de aquélla en valores seguros, lícitos y fructíferos; pero queda prohibido en absoluto gastarla de cualquier forma antes que la religiosa muera, ni siquiera para edificar casa o para pagar deuda.. (Canon 549). Las dotes deben ser administradas cuidadosa e íntegramente en el monasterio [...] Los Ordinarios del lugar velarán diligentemente por la conservación de las dotes; y sobre todo en la santa visita exijan que se les de cuenta de las mismas (Canon 550). A la religiosa profesa tanto de votos solemnes como de votos simples, que salga del Instituto por cualquier motivo que lo haga, se le ha de restituir la dote íntegra sin los réditos ya vencidos. Pero si una religiosa profesa pasa con indulto apostólico a otra religión, durante el noviciado, salvo lo establecido en el canon 570, los frutos de la dote se deben entregar a la nueva religión, y después que profese, también la dote; si pasa a otro monasterio de la misma Orden, a él se ha de entregar la dote desde el día mismo del tránsito, (Canon 551). Código de Derecho Canónico. Bilingüe y comentado, prologado por fray José López Ortiz, BAC, Madrid, 1957.

${ }^{28} \mathrm{Al}$ inicio las monjas destinaron en parte los capitales dotales para el mantenimiento y construcción del monasterio. De hecho, en 1619 el obispo Julián de Cortázar había ordenado a las Catalinas que levantaran la cerca de la huerta del monasterio: «la cual dicha cerca mandamos se haga del dinero del primero docte de la primera religiossa que profesare en el dicho convento y sino bastare se acaue de hazer con las rentas del dicho convento». R. LeVILLIER (dir.), Papeles eclesiásticos..., vol. I, Madrid, Imprenta de Juan Puello, 1926, pp. 162-162.

${ }^{29}$ El censo consignativo era un préstamo a muy largo plazo. En la operación, el acreedor entregaba una suma de dinero al deudor; éste gravaba un bien raíz y no determinaba una fecha para la devolución, la cual quedaba abierta y a merced del deudor. El deudor, por su parte, se comprometía a pagar los réditos mientras no redimiese el principal. Jurídicamente el censo era una venta y no un préstamo. El acreedor compraba los derechos a percibir una renta anual (réditos) y a cambio entregaba al deudor una suma de dinero (principal). De este modo la redacción del contrato seguía el modelo de una escritura de compraventa y no de préstamo. El censo era un derecho real que reposaba, en primer término, sobre un bien raíz, de ahí que fuese el poseedor del bien quien debía satisfacer el censo. Esto implicaba que si se trasladaba la propiedad, se trasmitía también la carga sobre la misma, y que la compra de una pro-

Hispania Sacra, LX

122, julio-diciembre 2008, 423-443, ISSN: 0018-215-X 
La comunidad inició su carrera como unidad financiera en su segunda década de vida. Da cuenta de ello el censo a favor del monasterio de Santa Catalina que impuso sobre la estancia Navidad su dueña doña Lucía de Mansilla el 24 de agosto de $1624^{30}$. Si bien periódicamente se registra la escritura de algún censo, a partir de la quinta década del siglo se produce un aumento considerable en ese tipo de actividad. Entre otras, el 19 de enero de 1645 las monjas firmaron una escritura de censo otorgada por Jerónimo Juárez de mancomún con doña Elena de Puellez, su mujer, sobre sus casas, tierras y estancia llamada Colombo, a diez leguas «destante de esta Ciudad (...) por razón de que por su compra las dhas señoras Priora y monjas nos dan y pagan de presente y nosotros recivimos en presencia del Presente Escrivano Quinientos pesos corrientes que es su principal arrazon de veinte mil el millar conforme a Leyes de estos reynos todo en reales de plata de a ocho reales cada uno». El matrimonio se comprometía, a su vez, a pagar, «a las dhas señoras Priora y monjas de dho Monasterio, que son y a las que adelante fueren y a quien su Dro. huviere, los dhos veinticinco pesos de esta renta de censso a Diez días del mes de enero de cada un año y será la primera paga a Diez días del mes de enero del año que viene de mil ceicientos y quarenta y seis y desde allí en adelante para siempre jamás por el dho plazo hasta que se redima».

Para entonces la masa de deudores censales y las sumas otorgadas en préstamo habían aumentado notablemente ${ }^{31}$. El 12 de mayo de 1647 Francisco Rodríguez vendió a las monjas dos arrobas y media de jabón, a cuatro pesos la arroba, «a cuenta de los mil pesos de censo que tenía». Por su parte, ese mismo año, don Francisco de la Cámara, para saldar sus deudas con las Catalinas, entregó

piedad acensuada o gravada con censo, hacía posible su adquisición a crédito, ya que en el momento de formalizar una escritura de venta, se descontaba al comprador el principal del censo del importe y éste, a cambio, se comprometía a reconocerlo, es decir a pagar los réditos del mismo hasta su redención o mientras mantuviese la titularidad de la posesión. De este modo, la adquisición de propiedades acensuadas permitía el crédito por medio de un menor desembolso de dinero efectivo. Para una lectura comparativa y una definición más amplia véase, María del Pilar MARTínez LóPEZ-CANO, «El crédito eclesiástico en Nueva España», América Latina en la Historia Económica, nº 6 (1996), pp. 9-19; G. VON WOBESER, El Crédito Eclesiástico en la Nueva España, México, Universidad Nacional Autónoma de México, 1994, pp. 17, 39, 40.

${ }^{30}$ AHPC, R 1, prot. 1624-26, fs. 192r-197r.

${ }^{31}$ A modo de ejemplo, en 1584 los Cabrera -descendientes del fundador de la ciudad de Córdobahabían recibido en merced una estancia en Costasacate, a las márgenes del río Segundo, en el camino a Buenos Aires. Pronto sus dueños se dedicaron a la producción ganadera. En 1641 y en 1649 la estancia, que hasta entonces estaba libre de deudas, cargó con dos censos, ambos vendidos al monasterio de Santa Catalina. Asimismo, el 13 de abril de 1651 don Ignacio de Acevedo impuso un censo en el monasterio de Santa Catalina por el valor de 400 pesos, cargándolos sobre «las tierras y estancia que tengo en el río Segundo nueve leguas de esta ciudad que lindan con tierras y estancias de Manuel Rodríguez y de Francisco Rodríguez Enríquez con sus ganados de yeguas de cría de mulas». M. del C. FerReYra, Las estancias del Río Segundo, Junta Provincial de Historia, Córdoba, 2004, pp. 22-25, 68-70, 116$117,181$. 
tres fanegas de maíz, a cinco pesos y medio la fanega, y veinticinco pesos más. Cámara dio también, a finales de ese año, carne, grasa, sebo y otros diez pesos. Asimismo, don Gerónimo Juárez dio al monasterio, desde 1645, cuarenta pesos en reales e hizo varias entregas de pan. Manuel de Deza pagó sus deudas con cinco pesos y medio de reales en 1648, más un almud de azafrán por seis reales, más cinco reales de papas, cuatro fanegas de harina a cuatro pesos la fanega. Francisco de Vilches pagó sus deudas con fanegas de trigo ${ }^{32}$.

Los pagos se realizaban todavía con puntualidad, tal como lo demuestra el libro de la procuradora, pero con mucha frecuencia en «frutos de la tierra». De este modo, los intercambios económicos que se establecieron entre el monasterio y el resto de la sociedad cordobesa eran acordes con la estructura comercial típica de la época, en virtud de la coexistencia de una economía natural y una economía monetaria, predominando en los cambios y pagos locales la «moneda de la tierra», salvo en los negocios de esclavos; mientras que los cambios del gran comercio a distancia (con el Potosí o con el Brasil) se hacían con pesos de plata de a 8 reales ${ }^{33}$.

Todos los ingresos en especies servían, en general, para alimentar a las monjas y a su creciente personal de servicio -sirvientas y esclavos- mientras que el metálico, además de ser utilizado en el otorgamiento de créditos, servía a la hermana procuradora para pagar las compras de género mayor (esclavos) y las continuas obras de construcción y mantenimiento realizadas esos años en la fábrica monástica. En efecto, debido a las roturas causadas por el desborde de la Cañada en 1622, al deterioro general del edificio y a la peste de 1635, la casa que hasta entonces ocupaban las monjas se había hecho ruinosa e insalubre, por cual habían decidido comprar otro predio y construir en él un nuevo monasterio. Desde 1637 hasta 1652, cuando quedó inaugurada la iglesia, los esfuerzos económicos de las Catalinas estuvieron dirigidos al acondicionamiento de los nuevos edificios ${ }^{34}$.

De todos modos, con la ayuda del obispo se pudo realizar el traslado del monasterio. En 1638 fray Melchor Maldonado, obispo del Tucumán, en visita canónica a su diócesis, visitó el Convento de Santa Catalina, «y por estar sus cercas, sus dormitorios y su iglesia, todo caído, y ser imposible obrar en él, compró unas casas principales y buenas, en diez mil pesos, para que se muda-

\footnotetext{
${ }^{32} \mathrm{El}$ elenco presentado es una pequeña fracción de los deudores del monasterio de Santa Catalina a mediados del siglo XVII.

33 Véase, C. GARZÓN MACEDA, Economía del Tucumán. Economía natural y economía monetaria, Córdoba, Universidad Nacional de Córdoba, 1968, pp. 4-18.

${ }^{34}$ Así se comprende el destino de los 25 pesos que aportó don Francisco de la Cámara a cuenta de sus numerosas deudas con las monjas. De ellos fueron deducidos 15 para comprar «tres hachas para ir al monte a cortar la madera para la iglesia y los diez (restantes) se dieron a Enrique», empleado por las religiosas para esa tarea.
}

Hispania Sacra, LX

122, julio-diciembre 2008, 423-443, ISSN: 0018-215-X 
se» ${ }^{35}$. Además «aumentó» a las monjas, con el cobro de algunas deudas, casi cuatrocientos pesos de renta. Al final de su visita volvió al monasterio y las hallo mudadas «a las casas nuevas, hizo acabarles cerco y todo en redondo, dejó cuarenta mil tejas pagadas, dejó la piedra traída para la iglesia y toda la madrea de cedro, nogal y tablas llevadas de Tucumán para que le sobre, y dejó señaladas ditas y dineros par la fábrica y cerca, dejó vendidas unas casas del dicho convento que se le iban perdiendo, y para rematar las casas que eran convento viejo y orden de que se rematasen ${ }^{36}$. Finalmente, don Gaspar de Salinas compró el edificio viejo por 2200 pesos el 27 de febrero de 1640. La construcción del templo se inició en 1645 y fue inaugurado en Pascua de Resurrección del año 1652.

\section{CRISIS ECONÓMICA Y MUTACIÓN SOCIAL}

Durante la segunda mitad del siglo XVII la economía del área tucumana, y con ella la cordobesa, se vio afectada por la crisis minera del Potosí. Es bien conocido que, desde mediados de dicha centuria, la escasez general de numerario fue la causa de las continuas solicitudes de exenciones y privilegios -con los acostumbrados lamentos por la falta de moneda- que la mayoría de las ciudades vinculadas al circuito altoperuano dirigieron al Rey ${ }^{37}$.

Específicamente, en el caso de Córdoba, la escasez era el producto directo de la creciente depreciación del valor otorgado a los «frutos de la tierra» en general, entre los que se incluye al principal producto de exportación de su territorio, las mulas ${ }^{38}$. La ciudad y jurisdicción de Córdoba exportaba hacia 1650 unas 12.000 cabezas. El desarrollo y éxito de la producción local situó la media anual de mulas exportadas, a lo largo de la segunda mitad del siglo XVII, en el

35 J. C. Vera Vallejo, Op. Cit., pp. 150-152.

36 S. Palomeque (dir.), Actas del Cabildo Eclesiástico. Obispado del Tucumán con sede en Santiago del Estero 1592-1667, Córdoba, Ferreira Editor, 2005, pp. 358.

${ }^{37}$ En 1668 el cabildo de la ciudad de Córdoba en una representación a la reina doña Mariana de Austria, en la que solicitaba le fuera permitido introducir por el puerto de Buenos Aires mercancías y esclavos, expresaba que la falta de dinero llega en toda la Provincia (se refiere a la gobernación del Tucumán) a tanto que ni aún para el comercio ordinario del sustento apenas corre plata, por no hallarse ni viene de fuera, por cuya causa falta la venta de mulas a los que del Perú venían a comprarlas para el trajín de aquellas tierras; pero hoy a cesado ese comercio, de suerte que no hay quien pague dos pesos por una mula de año y no en plata sino la mayor parte o todo en ropa (Publicado en Documentos Históricos y geográficos relativos a la Conquista y Colonización Rioplatense, tomo I, Buenos Aires, Editorial Peuser,1941, p. 259).

38 Carlos Sempat Assadourian, «Potosí y el crecimiento económico de Córdoba en los siglos XVI y XVII», en Homenaje al doctor Ceferino Garzón Maceda, Córdoba, Universidad Nacional de Córdoba, 1973, pp. 169-183. 
orden de los 20.000 ejemplares ${ }^{39}$. Sin embargo, los precios de venta de las mulas en el Alto Perú habrían sufrido una fuerte caída a lo largo de la centuria, llegando a situarse a partir de 1660 a menos de 10 pesos de reales por animal, cuando hacia 1650 se cobraban a 30 pesos y a principios de siglo habían llegado incluso a la extraordinaria suma de 60 pesos $^{40}$.

En consecuencia, las Catalinas, y con ellas muchos productores cordobeses, tuvieron dificultades para vender sus mulas a buen precio o para cobrar a sus deudores censales ${ }^{41}$. De hecho, los pagos comenzaron a aplazarse y las rentas a perderse. No obstante, el problema principal de la economía conventual residía en que aquellas rentas que eran pagadas, en general no eran satisfechas en metálico, como se debía, sino en frutos y efectos de la tierra, con lo cual -a raíz de la progresiva caída de los precios de los productos agropecuarios del Tucumánse depreciaba el valor mismo de la renta, que debiendo ser del $5 \%$ sobre el monto del principal, terminaban siéndolo al 3\% según el valor de cambio de esos géneros en el mercado local ${ }^{42}$. De allí que, en el cuadro de una economía

${ }^{39} \mathrm{Si}$ el valor de las mulas se vio depreciado a raíz de la falta de metálico y del aumento de la oferta, el crecimiento sostenido de la demanda de animales -vendidos en buena parte de la segunda mitad del siglo XVII- se debió al aumento de la población de las ciudades altoperuanas, incluida la Villa Imperial, y a las necesidades de trasporte de unas explotaciones mineras que se dispersaron en esa región gracias a la misma decadencia productiva potosina. Recuérdese que en el Alto Perú existían otros reales de minas, tales como Oruro, cuya capital llegó a concentrar una población de 70.000 almas hacia 1670. De todos modos, la fortuna económica de algunos ganaderos y comerciantes de mulas de Córdoba, justamente en la segunda mitad del siglo XVII, habla de la capacidad de respuesta de la economía local a la crisis económica general del espacio peruano. Véase, Zacarías MouTOUKIAS, «El comercio interregional», en A. CASTILLERO CAlvo (dir.), Historia General de América latina, III 1. Consolidación del Orden Colonial, Paris, UNESCO/Trotta, 2000, pp. 133-149; Ana Inés FERREYRA, «Patrimonio y producción en las tierras de los betlemitas. Córdoba, 1600-1870», Mundo Agrario, vol 7 n 14 (2007).

${ }^{40}$ Hay que decir que las estimaciones de los precios de las mulas, si bien demuestran una tendencia decreciente, son tópicas. Tal como se ha demostrado recientemente, el precio de una mula se ajustaba en realidad a la calidad, condiciones, edad e incluso habilidades del equino. Por lo tanto, en el mercado no existía un único precio. Véase, Ana Inés FERREYRA, «Tierra, trabajo y producción en el Interior del país. Una unidad de producción en Córdoba, 1600-1870», en Anuario del IEHS, n 20 (2005), pp. 183-210.

41 Todavía en 1729, el obispo Sarricolea y Olea, se lamentaba de la impotencia del monasterio dominico que no lograba hacerse con el dinero de sus deudores: Llegando a llorarse como escándalo de iniquidad, este que se admiraba exemplo de tanta edificación [...] viendo, que ni los Censuatarios las acudian con los Reditos de los censos, por mas diligencias que hiciese la buena solicitud, ni los jueces se resolvían a mandarlo, por mas que se multiplicase su clamor. AAC, Catalinas, Rollo 7, Carta del obispo de Tucumán a Su Majestad dando cuenta de la visita de su diócesis. Córdoba del Tucumán, 20 de abril de 1729 .

42 Al igual que en Córdoba, en la segunda mitad del siglo XVII todos los mercados vinculados al Perú sufrían por el progresivo deterioro de los precios de los productos agropecuarios, cuya venta no alcanzaba a compensar los precios de los productos de importación, los así llamados «efectos de Castilla», dando como resultado unos términos de intercambio desfavorables. Dicha situación explicaría, en el caso de Córdoba, el creciente recurso a los productos ingresados por vía de contrabando a través del puerto de Buenos Aires. Véase, R. Romano, Mecanismo y elementos del sistema económico colonial

Hispania Sacra, LX

122, julio-diciembre 2008, 423-443, ISSN: 0018-215-X 
semi-monetarizada, el numerario suficiente para hacer frente a los crecientes gastos de la comunidad tendió a desaparecer.

En esas condiciones, una de las primeras estrategias adoptadas por las monjas para adquirir una mayor cantidad de bienes de cambio fue la venta o el «canje» de alguna de sus propiedades rurales. Tal el caso de la estancia de Guamacha, que habían recibido de la fundadora, y de la hijuela adyacente, que era pago de dote de sor Mariana de los Ángeles, una de las primeras compañeras de Leonor de Tejeda, que fue traspasada en 1641 a don Hernando de Tejeda ${ }^{43}$. Otro tanto se puede decir de la venta de la estancia de Cantala, propiedad que había sido de Hernando de Tinoco, adquirida por las monjas como pago de los réditos atrasados de un censo que gravaba esa propiedad, que finalmente vendieron en 1648 a Francisco de Vilches «con los ganados mayores y menores que tiene, yeguas y garañones asnos conforme tasación» 44 . Dineros que seguramente fueron invertidos en la fábrica del monasterio y en la construcción de su iglesia. Asimismo, la venta de una casa en la ciudad, por el monto de 3.000 pesos, sirvió a las monjas para comprar a los padres dominicos el cuarto solar que aún no poseían de la manzana donde estaba emplazado el monasterio de Santa Catalina ${ }^{45}$.

Al comprobar que con el paso del tiempo la crisis económica de la región no remitía, las monjas optaron por el arrendamiento de otras propiedades más valiosas. Tal como sucedió con la estancia de Macha, en 1672, cuando resolvieron encomendar la realización de una mensura de su superficie al agrimensor Ignacio de Loyola y Zavala para proceder a su arrendamiento. Uno de los arrendatarios fue don Juan de Figueroa y Mendoza, quien lo hizo durante cincuenta años, hasta 1731. Para esa época, el casco principal de esa estancia estaba compuesto por varias edificaciones de piedra asentadas en barro, con techos de paja, con un molino hidráulico, una represa de media legua de largo, más chacras y sembradíos de trigo ${ }^{46}$.

Hay que decir que las Catalinas, tal como disponían sus constituciones, seguían invirtiendo las sumas de las dotes de las profesas en censos, que, a partir de entonces, gravaron sobre todo propiedades establecidas dentro de la ciudad de Córdoba. Esos censos descubren los graves problemas económicos que en-

\footnotetext{
americano. Siglos XVI-XVIII, México, Fideicomiso Historia de las Américas, 2004, pp. 376-388; José Manuel LARRAIN, «Los términos de intercambio en una economía colonial. El caso de Chile en los siglos XVII y XVIII», América Latina en la Historia Económica, n 5 (1996), pp. 51-67; Z. MoutouKIAS, Contrabando y control social. Buenos Aires entre el Atlántico y el espacio peruano en el siglo XVII, Buenos Aires, Centro Editor de América Latina, 1989.

${ }^{43}$ AHPC, R. 1, Prot. 1641-1642, fol. 93.

${ }^{44}$ M. del C. FERREYRA, Op. Cit., p. 142-144.

${ }^{45}$ AHPC. Prot., leg. 81, f. 75v.

${ }^{46}$ L. Calvimonte, A. Moyano Aliaga, El antiguo Camino Real al Perú en el Norte de Córdoba, Córdoba, Ediciones del Copista, 1996, pp. 92-94.
} 
frentaban algunas familias de la elite tradicional, ya que un buen número de ellos -sobre todo los tasados a 1.500 pesos y más- ocultaban verdaderas hipotecas destinadas a pagar las dotes de las novicias. Los padres de las monjas ponían como garantía las propias viviendas familiares, establecidas en la traza de ciudad, casas que con frecuencia perdieron porque no pudieron levantar los censos en los dilatados plazos estipulados ${ }^{47}$.

Hacia 1682, el número de profesiones decayó repentinamente, y con ello el dinero de las dotes. Para mejorar la apretada situación de sus finanzas las monjas se decidieron a utilizar un expediente hasta entonces desdeñado o desconocido. A fin de permitir el ingreso y la permanencia de una mayor cantidad de religiosas -que con sus dotes y legados aportaran el ansiado numerario- las superioras del monasterio dominico permitieron que ciertas normas constitucionales de la vida monástica comenzasen a ser alteradas. De ese modo, se dio paso a la formación de un tipo comunitario distinto al previsto por los estatutos en vigor y también diferente a la comunidad que hasta entonces se había congregado bajo esos muros conventuales ${ }^{48}$.

Si bien la recepción de novicias de las principales familias cordobesas no era una novedad para el capítulo conventual -es más, se trataba de una norma introducida por la misma fundadora- a partir de entonces sí lo fue la desatención de la vida comunitaria que esas nuevas profesas introdujeron en las costumbres de la casa. Esto se debía a que sus familiares obtenían, con el consentimiento de los gobernadores episcopales, de las prioras conventuales y del capítulo monástico, la autorización para que las nuevas pudieran tener dentro del convento celda propia, con cocina, sirvientes e incluso, a veces, con capilla, en virtud del pago de una cuantiosa dote, mejorada con otros bienes que esas religiosas aportaban al monasterio. Situación que, a su vez, redundó en el esta-

\footnotetext{
${ }^{47}$ A medida que se aproxima el fin de siglo los censos se radican sobre casas en la ciudad. En general se observa que los síndicos del monasterio no retenían las propiedades -rurales o urbanas- que las monjas recibían en legado o que expropiaban a causa de la falta del pago de censos, sino que las revendían de inmediato para hacer uso del dinero en los gastos de la comunidad. Véase, C. LuQue Colombres, Orígenes históricos de la propiedad urbana de Córdoba (siglos XVI y XVII), Córdoba, Universidad Nacional de Córdoba, 1980, pp. 241, 242, 250, 258, 261, 262, 273, 275, 277, 278, 281, 284, 298.

${ }^{48}$ Es cierto que la situación y los recaudos tomados por las monjas cordobesas no se diferencian en mucho a los de sus equivalentes españoles en la misma época. Sin embargo, los monasterios españoles -ya fueran aquellos poderosos como los menos favorecidos- frente a una angustiante situación económica que tendió a instalarse desde finales del siglo XVI, se veían generalmente obligados a recurrir a la piedad real para poder sanear sus finanzas, expediente al que no tuvo que recurrir jamás el monasterio de Santa Catalina. Manifestación de unas condiciones económicas diferenciales respecto a la peninsular. Sobre la crisis de los monasterios españoles sigue siendo de referencia obligada el clásico estudio de A. Domínguez Ortiz, Las clases privilegiadas en la España del Antiguo Régimen, Madrid, Ediciones Istmo, 1973, pp. 321-336.
}

Hispania Sacra, LX

122, julio-diciembre 2008, 423-443, ISSN: 0018-215-X 
blecimiento de una estrecha -y nueva- vinculación de las monjas de Santa Catalina con las fortunas en ascenso en esa época ${ }^{49}$.

El número de monjas aumentó notablemente, en virtud de la nueva forma de reclutamiento. Efectivamente, de las 104 religiosas que profesaron en la segunda mitad del siglo XVII, cuarenta lo hicieron en los últimos quince años de esa centuria $^{50}$. Los apellidos de esas últimas delatan una gran afluencia de mujeres venidas de regiones distantes a la jurisdicción de la capital cordobesa, con un notable número de porteñas, prácticamente inexistentes hasta entonces. Muchas de ellas son parientes entre si: hay dos hermanas Herrera y Velasco y Carranza, tres hermanas Cabrera Carranza, dos Gaete y Bazán, tres Arregui, tres Ceballos Neto y Estrada, dos Orantes y Adaro, y dos Pacheco y Salinas, sin contar las tías y primas. Una explicación a la existencia de relaciones parentales tan estrechas dentro del claustro monástico estaría dada por el aumento del número de miembros en las familias de las elites y el temor de los padres a ver disueltos los patrimonios familiares. En general esas mujeres solían entrar en el monasterio a temprana edad para ser educadas por una tía o hermana mayor hasta que tuvieran la edad suficiente para profesar (dieciséis años).

Por otra parte, la existencia de una nutrida parentela en el monasterio y la posesión de una buena celda legada por sus familiares, compensaban de algún modo la pérdida afectiva y la desinversión social que sufrían muchas de esas mujeres, a veces recluidas allí sin una verdadera vocación al claustro. Resulta evidente que la decisión de permanecer en el convento dependió, para la mayoría de esas jóvenes, de haber constatado los numerosos cuidados y las extraordinarios atenciones tomadas hacia ellas por sus familiares ${ }^{51}$. Como sea, se trata de

${ }^{49}$ Las Catalinas consiguieron finalmente el dinero que necesitaban, lo pone de manifiesto el nuevo impulso que cobró el crédito otorgado por las monjas, cuyas cifras se sitúan en el orden de los 1.000 a 4.000 pesos. Ibidem, pp. 288, 301, 305, 310, 319, 320, 313, 314, 321, 336, 340, 343, 344-345, 349, 352-353, 367, 381, 383, 396.

${ }^{50}$ AAC, Catalinas, Rollo 1, Tabla cronológica que propone todas las religiosas que desde la Fundación hasta nuestros tiempos han profesado en el monasterio de Santa Catalina de Sena de la ciudad de Córdoba, pp. 16-27.

${ }^{51}$ El apoyo familiar en la consolidación de una vocación religiosa femenina era de capital importancia. Rafaella Sarti cuenta una historia que está en el otro extremo del caso de las Catalinas de Córdoba que, hasta donde nosotros sabemos, nunca abandonaron el claustro. Una joven noble romana, Olimpia Battista, había sido llevada por sus hermanos a un convento en el cual esperaba decidir su futuro. Para ella, dice, como para las otras adolescentes, la alternativa era el convento o el matrimonio, es decir, «muro o marido». La decepción de su hermano Giovanni fue enorme cuando se le comunicó que ella no quería hacerse monja. ¿Cuál fue la razón por la que Olimpia no quiso profesar? La conocemos por escritos de su otra hermana, Geronima Veralli, quien recrimina a Giovanni el haber abandonado a Olimpia, no haberle proporcionado cuidados, ni ropa de cama, ni dinero. Vista la situación, la joven dedujo que haciéndose monja sería «abandonada por todos», sin «tener nunca más un acercamiento ni una visita». Es así que Geronima lo reprende diciéndole que él «debería haberse ocupado de la hermana y haberla hecho sentir inmersa en la relación familiar, aunque estuviera dentro del monasterio. Si 
un fenómeno que, si bien se puede observar también entre el primer grupo que acompañó a doña Leonor de Tejeda, nunca había llegado a alcanzar la magnitud y las características que adquirió a finales del siglo XVII.

En esa época, y del mismo modo que lo habían hecho sus antecesoras, todas las monjas debían redactar un testamento de renuncia de la legítima, norma constitucional ineludible. Sin embargo, con mucha frecuencia la resignación de la herencia fue violada, ya que las profesas terminaron por aceptar legados y donaciones que recibían de sus padres, fruto de complicados arreglos previos a la entrada en la clausura monástica. Sirva de ejemplo el caso de sor María de la Encarnación, quien profesara el 20 de mayo de 1687 en manos de la vigésima cuarta priora del monasterio, la madre Juana de la Encarnación. Su padre, el capitán don Gregorio Díez Gómez en su testamento, redactado en el año 1688, había pedido ser enterrado con el hábito de San Francisco en el Convento de Nuestra Señora de la Merced ${ }^{52}$. De sus bienes, dejaba limosnas a varias instituciones religiosas. Sin embargo, un amplio espacio ocupa entre sus mandas testamentarias las dirigidas a su hija doña María Diez Gómez, en religión sor María de la Encarnación. A ella legaba las casas de su morada, cuyo valor ascendía a 4.000 pesos -que en ese momento ocupaba su esposa- para que disfrutase de todas sus rentas y alquileres «por todos los días de su vida para que con ellos y con lo demás que se dirá, tenga con que poder suplir las necesidades que suelen experimentar las religiosas de los monasterios de esta dicha ciudad por no poderles acudir sus Preladas muchas veces como quisieran aun con lo necesario».

Además, desconociendo el testamento de renuncia del 12 de mayo de 1687 que sor María había hecho a favor de su padre, en el que se había reservando el dinero suficiente para la paga de la dote y propinas al monasterio, don Gregorio ordenaba que:

«por quanto con las rentas y alquileres de las casas no tendría la dicha su hija para lo que con el tiempo se le pudiese ofrecer y es que así se lo tenia ofrecido desde antes que profesase, se le impusiesen quatromil pesos de principal a pesos de la primera plata que viniese de las mulas, que como de se avran de enviar a vender a Salta de los quales aya y perciba la dicha su hija ducientos pesos de renta todos los años por todos los días de su vida. Y que la cobranza asi de los dhos ducientos pesos de renta, como de los alquileres de dichas casas llegado que sea el caso después de la muerte de la dha su mujer [Ana María Bustos de Albornoz] si la dha su hija como mujer y religiosa, necesitasse de quien en este cuydado y solicitud la ayudasse, corriesse por la solicitud y cuidado del Maestre de Campo Diego Diez Gomez su hermano [...] o sino del capitán Gregorio Diez Gomez o del capitán Francisco Diez Gomez [hermanos de María]».

eso hubiera sido así, probablemente hubiese tomado el velo». R. SARTI, Vita di casa. Abitare, mangiare, vestire nell'Europa moderna, Roma, Laterza, 2006, pp. 27-30.

${ }^{52}$ AAC, Catalinas, Rollo 3, Testamento del capitán Gregorio Díez Gómez.

Hispania Sacra, LX

122, julio-diciembre 2008, 423-443, ISSN: 0018-215-X 
A la muerte de la madre y de la hija monja el alquiler de las casas debía pasar a conformar una capellanía de misas a favor del Convento de la Merced, mientras que María de la Encarnación podía dejar los cuatro mil pesos de censo sobre las mulas al Monasterio, su heredero universal. Además don Gregorio dejaba a sor María dos esclavas, que ella debía elegir entre las que servían en la casa de su padre. Se quedaría también con la plata labrada de su casa, «de la qual sabe el Alférez Real B. Enrique de Cevallos Estrada, con mas dos tembladeras* de dos marcos, mas como las pidiese las dicha su hija que se le mandaran aser y dos caras las que escogiere y mejor le parecieren a la dha su hija de las que el dho difunto tenia en su casa con un escritorio grande que es el mayor que tenía».

Por otra parte, Gregorio Diez había celebrado un trato con don Diego Salguero de Cabrera, vicario y juez ordinario de los monasterios de monjas de Córdoba, para que en merced «se mandase aser una celda a la dha su hija del grandor, tamaño y forma que tenían comunicado [en el] lugar que la madre Priora de dho Monasterio le tiene señalado; y por quenta de la dha celda se le hubieren de dar al dho Vo. D. Diego Salguero de Cabrera trescientas mulas de las nacidas este año de mil seiscientos y ochenta y ocho imbernadas un año». La madera para dicha celda, que había comprado con anterioridad a Valeriano y Diego Álvarez, se la entregaba Díez Gómez a Salguero, quien pagaría a su vez en plata el costo de la obra, «y porque fue su voluntad de dho difunto que se cumpliese dho trato y se hiciesse la dicha celda para la dha su hija lo mas capaz y mejor que se pudiesse con todo lo que ella pidiere en ella sin reparar en su gasto y costo» ${ }^{53}$.

El resto de las mandas testamentarias son numerosas, ya que don Gregorio dejaba ayudas a hijos, sobrinos y otros deudos. Finalmente, dejó como última voluntad que se pusieran en buen orden sus cuentas y se pagasen los diezmos que adeudaba. Don Gregorio era un hombre rico, tenía una hacienda de mulas enorme y negocios comunes con sus hermanos y con su amigo Enrique de Cevallos. De hecho, su riqueza se había acrecentado inmensamente gracias a las mercedes de tierra que en Río Tercero le había concedido el Gobernador Tomás Félix de Argandoña.

Pronto, ese tipo de tratos había llevado al monasterio de Santa Catalina a adquirir los rasgos de una aldea femenina, dirigida por un grupo numeroso de re-

\footnotetext{
* La tembladera era un vaso ancho de plata, oro o vidrio, de figura redonda, con dos asas a los lados y un pequeño asiento. Las hay de muchos tamaños, y se hacen generalmente de una hoja muy delgada que parece que tiembla. Servían para contener alimentos líquidos en la mesa.

${ }_{53}$ María recibió las casas tras el fallecimiento de su madre, doña Ana Bustos de Albornoz, el 17 de noviembre de 1689 (don Gregorio había fallecido el 28 de febrero de 1688). Las vendió por 3.500 pesos a Bartolomé de Olmedo el 20 de octubre de 1694. Hacia 1727, María era priora del monasterio de Santa Catalina. AHPC, Prot., leg. 83, fs. 50 y 82; leg. 88, f. 634.
} 
ligiosas (más de cincuenta) que llevaban una vida comunitaria sumamente mitigada $^{54}$. Rodeadas por familiares, las monjas convivían en sus celdas con educandas y se hacían servir por dos o tres criadas «enclaustradas», sobrepasando holgadamente el número permitido 55 .

En sus celdas, algunas monjas colgaron óleos de tradición cuzqueña -donación de sus padres- que representaban la vida de Santa Rosa de Lima o de Santa Catalina de Siena, testimonio de una devoción en alza en el cenobio cordobés ${ }^{56}$. Paradójicamente, las dos santas dominicas habían sido en realidad hermanas de la Tercera Orden. Sin embargo, esos lienzos resultaban atractivos para las monjas Catalinas de Córdoba por su capacidad para relatar una historia sacra, muchas veces signada por el apego a la vida penitencial, por el amor a Cristo crucificado -motivos caros a la cultura eclesiástica del barroco- y, sobre todo, porque proponían un camino espiritual mas bien «individual», transcurrido en la soledad de la propia celda, modelo cercano al que ellas mismas transitaban, ya que Catalina primero y Rosa después se habían recogido en celdas construidas en el fondo de sus propias casas y no habían querido o podido vivir en comunidad ${ }^{57}$.

${ }^{54}$ La población monástica, incluyendo sirvientas y esclavos, habría sobrepasado las trescientas almas a finales del siglo XVII. En 1680 el padre Diego Altamirano, Procurador General de la Compañía de Jesús, dice que en Córdoba: hay un convento de monjas Carmelitas Descalzas que pasan de veinte pocas más según su regla; y otro de monjas de Santo Domingo que suele tener ochenta (Documento citado por C. Bruno, Historia de la Iglesia en la Argentina, vol. II, Buenos Aires, Editorial Don Bosco, 1969 , p. 408). Véase además, Guillermo Nieva OCAMPo, Ana Mónica GonZÁLEz FASANI, «Relicario de Vírgenes. Familia monástica en el convento de Santa Catalina de Córdoba del Tucumán (1730-1750)», en C. Folquer (ed.), La Orden Dominicana en Argentina: Actores y Prácticas, San Miguel de Tucumán, Editorial UNSTA, 2008, pp. 23-54.

55 A veces esas criadas entraban a la clausura siendo niñas, tal como le sucedió en 1693 a sor Petronila de la Encarnación -monja de velo blanco- cuando recibió, según la última voluntad de su madre, una esclava negra llamada María que para entonces tenía nueve años. Esta monja -Petrona de Soto según su nombre en el siglo- ya había recibido de su padre la dote «competente» para profesar y una negrita llamada Bernacha para que la atendiera. AAC, Catalinas, Rollo 3, Testamento de María de Soto.

${ }^{56}$ En el monasterio se conservan actualmente dos series de pinturas sobre la vida de Santa Rosa y de Santa Catalina, varios cuadros que pertenecieron a siete series de la vida de la Virgen María y un significativo número de óleos que retratan diversas advocaciones de la Virgen y de algunos santos. Los que corresponden a las santas dominicas están fechados en los años finales del siglo XVII. No fueron adquiridos por compra, sino que fueron recibidos por las monjas como parte de la dotación que sus familiares les otorgaban al entrar en religión. Tal como le sucedió a sor Gabriela de la Encarnación cuyo padre -un sevillano afincado en Córdoba que se dedicaba al comercio de mulas- declaró que en 1697 cuando profesó, la doté con mil pesos y gasté quinientos pesos más en hábito de profesión y piso (...) y después le hice una celda a mi costa con una capilla alhajada y colgada de cuadros de santa Rosa de santa María. AHPC, Escribanía 1-1723, legajo 249, expediente 3 (documento citado por S. BARBIERI, Patrimonio Artístico Nacional. Inventario de bienes muebles. Iglesia y Monasterio de Santa Catalina de Siena de Córdoba, Academia Nacional de Bellas Artes, Buenos Aires, 2006, pp. 24-25).

${ }^{57}$ La vida de Santa Catalina era conocida en el mundo hispánico desde que el cardenal Cisneros ordenara en 1510 la traducción de sus escritos y de su biografía. Por su parte, Santa Rosa de Lima había

Hispania Sacra, LX

122, julio-diciembre 2008, 423-443, ISSN: 0018-215-X 
Sin embargo, no existe ninguna acusación ni por parte de las mismas monjas, ni por parte de los prelados o de otra persona, de la existencia de escándalos o de serias irregularidades morales en el interior del Monasterio de Santa Catalina. Es más, la decisión de alguna de las mujeres que eligieron profesar con las Catalinas -tal el caso de las hermanas Arregui o de las hermanas Cevallos- estuvo motivada por el hecho que allí, a pesar de las mitigaciones señaladas, o gracias a ellas, las monjas practicaban una vida devocional intensa. Basta pensar que entre esas monjas estaban las futuras fundadoras del monasterio de Buenos Aires y, junto a ellas, las que acompañaron a don Juan de Sarricolea y Olea y también a don Antonio Gutiérrez Zevallos en la campaña reformista que esos obispos iniciaron a partir de 1729. Por otra parte, más de una señora eligió por esos años ser sepultada vistiendo el hábito de Santa Catalina, con profesión de monja en la iglesia del monasterio ${ }^{58}$.

Si bien, también es cierto que alguna religiosa, llegado el momento de su muerte, creyó entender que el estilo de vida que había cultivado en ese claustro resultaba insuficiente para alcanzar la propia salvación, lo cual la impulsó a instituir una capellanía de misas por la gentil suma de 1000 pesos, para que las demás monjas rezaran por su alma ${ }^{59}$.

Sería, finalmente, el obispo Manuel Mercadillo, a raíz de una obligada visita canónica practicada en el año 1700 -cuando fue trasladada la sede episcopal de Santiago del Estero a Córdoba y la iglesia de las Catalinas se había convertido en catedral provisoria- quien advirtiese a las monjas de las «muchas y graves incomuniones» que se cultivaban en su monasterio, resultado de la atención a deshora en las puertas y locutorios, así como de las insólitas libertades que se tomaban las religiosas en el uso de indumentarias extrañas al hábito reglamentario, como las mantillas, rebozos y el andar con la basquiña o saya interior descubierta $^{60}$. Por ello ordenó a la priora la observancia de la clausura y de las ordenaciones constitucionales sin excepciones. La visita de ese obispo era el preludio de una reforma más profunda y más continua que llevarían a cabo sus sucesores en mejores tiempos.

sido beatificada en 1668 y canonizada en 1671, convirtiéndose inmediatamente en motivo de devoción e imitación en los monasterios femeninos de la América española. Un estudio general sobre los modelos de santidad en época barroca en Simon DitChField, «Il mondo della riforma e della Controriforma», en A. Benvenutti et al., Storia della santità, Roma, Viella, 2005, pp. 261-329. Véase además, G. Anodal, Caterina da Siena, Piemme, Asti, 2000; T. Hampe Martínez, Santidad e identidad criolla. Estudio del proceso de canonización de Santa Rosa, Cuzco, Centro Bartolomé de Las Casas,1998; R. Millar CARVACHO, «Rosa de Santa María (1586-1617). Génesis de su santidad y primera hagiografía», Historia, 36 (2003), pp. 255-273.

${ }^{58}$ Catalinas. AAC, Rollo 3, Testamento de María de Soto.

59 AAC, Catalinas, Rollo 4, 1693 la madre Juana del Espíritu Santo Instituye capellanía de \$50 por misas jueves y hace mención de haber entregado antes otros $\$ 500$ para el mismo objeto.

${ }^{60}$ AAC, Catalinas, Rollo 1, Libro de Visitas, Visita del año 1700. 